\title{
Chronic Treatment with the 5-HT1A Receptor Partial Agonist Tandospirone Increases Hippocampal Neurogenesis
}

\author{
Masayoshi Mori · Yusuke Murata • Asami Matsuo • \\ Tomoyo Takemoto $\cdot$ Kazunori Mine
}

To view enhanced content go to www.neurologytherapy-open.com

Received: October 15, 2013 / Published online: January 3, 2014

(c) The Author(s) 2013. This article is published with open access at Springerlink.com

\section{ABSTRACT}

Introduction: A large-scale clinical trial, the Sequence Trial Alternatives to Relieve Depression (STAR*D) study, concluded that about one-third of the studied patients with major depressive disorder remitted during the initial treatment with selective serotonin reuptake inhibitors and that approximately half of the remitted subjects relapsed over a 1-year follow-up. The development of new therapeutic approaches with potent efficacy and good tolerability for the treatment of depressive disorders is of great importance. Adult hippocampal neurogenesis has been proposed to be important for understanding and treating

Electronic supplementary material The online version of this article (doi:10.1007/s40120-013-0015-0) contains supplementary material, which is available to authorized users.

M. Mori · Y. Murata $(\bowtie) \cdot$ A. Matsuo · T. Takemoto Department of Psychosomatic Medicine, Faculty of Pharmaceutical Sciences, Fukuoka University, 8-19-1, Nanakuma, Jonan-ku, Fukuoka 814-0180, Japan

e-mail: ymurata@fukuoka-u.ac.jp

K. Mine

Faculty of Neurology and Psychiatry, Mito Hospital, Shime-Higashi, Shime-Machi, Kasuya-Gun,

Fukuoka, Japan depression and anxiety. The present study aimed to elucidate whether or not 5-hydroxytryptamine 1A (5-HT1A) receptor partial agonists have a potential therapeutic effect for the treatment of depressive and anxiety disorders, from the standpoint of neurogenesis.

Methods: Male Sprague-Dawley rats were subcutaneously administered a vehicle or tandospirone (TDS) (1 or $10 \mathrm{mg} / \mathrm{kg}$ ) once daily for 14 days. The effects of chronic TDS treatment on neurogenesis were evaluated on the day after the last injection. The quantification of hippocampal neurogenesis was estimated using immunostaining with doublecortin (DCX), a marker protein of newborn neurons.

Results: Chronic TDS treatment resulted in a significant increase in the number of DCXpositive cells per volume of dentate gyrus in a dose-dependent manner.

Conclusion: The results strongly suggest that 5-HT1A receptor partial agonists would be useful and beneficial in the treatment of depressive and anxiety disorders through increased hippocampal neurogenesis.

Keywords: 5-HT1A receptor partial agonist; Chronic treatment; Clinical efficacy; 
Depression and anxiety; Dose dependent; Doublecortin; Hippocampal neurogenesis; Novelty suppressed feeding; Tandospirone

\section{INTRODUCTION}

Depression and anxiety are common public health problems, affecting $5-10 \%$ of the world's population at any given time, and they share a high degree of comorbidity (up to 80-90\%) [1]. Although there are a number of medications available for the treatment of depressive and anxiety disorders, a considerable number of patients cannot achieve remission [2]. The Sequenced Treatment Alternatives to Relieve Depression $\left(\mathrm{STAR}^{*} \mathrm{D}\right)$ study, a large-scale clinical trial for major depressive disorder (MDD), demonstrated that only about one-third of the participants remitted during the initial treatment with citalopram and that approximately half of the remitted participants relapsed over a 1-year follow-up [3-5]. Baldwin et al. [6], in a review of previous studies of pharmacotherapies for generalized anxiety disorder (GAD), concluded that the remission rate is less than $60 \%$ for GAD patients treated with selective serotonin reuptake inhibitors (SSRIs). Therefore, the development of effective new therapeutic approaches with good tolerability for the treatment of depressive and anxiety disorders is of great importance.

Adult hippocampal neurogenesis has been proposed as important for understanding and treating depression and anxiety [7]. The hippocampus is not only involved in cognitive functions, but also is a key structure for regulating affective and anxiety states. The subgranular zone (SGZ) in the dentate gyrus (DG) of the hippocampus is one of only a few brain regions where the production of new neurons occurs throughout the lifetime of animals, including humans $[8,9]$. Accumulating evidence shows that adult hippocampal neurogenesis is decreased by stress and increased by chronic administration of antidepressants, such as fluoxetine [10, 11]. Thus, changes in adult hippocampal neurogenesis may be related to the pathophysiology of depressive and anxiety disorders and to the beneficial effects of antidepressant treatment $[7,9,12,13]$.

The azapirone drugs, including buspirone, tandospirone (TDS), and gepirone which act as 5-hydroxytryptamine 1A (5-HT1A) receptor partial agonists, have been widely used in the treatment of anxiety disorder [14, 15]. In practice, benzodiazepines are most frequently used in combination with standard antidepressants for the initial treatment and maintenance therapy for depressive disorders when comorbid anxiety exists [16]. We and many other researchers have shown that benzodiazepines produce drug dependence, sedation, and cognitive impairment in humans and rodents [17-20]. In contrast, azapirone-type 5-HT1A receptor agonists have the advantage of producing significantly fewer adverse effects than benzodiazepines and result in little dependence [21-23]. Recently, two animal studies revealed that co-administering benzodiazepines with antidepressants prevents an SSRI-induced increase in hippocampal neurogenesis, which suggests that the use of benzodiazepines delays the therapeutic onset and reduces the clinical efficacy of SSRIs [24, 25]. In contrast to above reports concerning benzodiazepines, 5-HT1A receptor agonists are considered to have an augmenting effect on clinical efficacy for depressive disorders when administered in combination with an SSRI. Recently, several authors have reported that 
augmentation therapy consisting of a combination of antidepressants with 5-HT1A receptor agonist treatment is a better therapeutic strategy for MDD than antidepressant monotherapy $[3,26,27]$.

In our previous pilot study, we showed that TDS, the only azapirone drug available in Japan, has excellent clinical efficacy for the treatment of GAD and mixed anxiety-depression and that it has no significant adverse effects [28]. We also showed that TDS had a remarkable anxiolytic effect in an animal model of anxiety and that the potency of the pharmacological effect was increased dose dependently, without a sedative effect [23].

In addition, we conducted a preliminary clinical study about the efficacy of augmentation therapy consisting of a combination of paroxetine and TDS (Sakamoto et al., unpublished data). In that study, among a consecutive series of 37 patients with MDD who were treated with the combination of paroxetine and TDS, 29 subjects (78.4\%) achieved remission at 12 weeks after the start of treatment. Furthermore, our 4-year follow-up study found recurrence in only $5(17.9 \%)$ of 28 patients who had remitted.

Thus, 5-HT1A receptor partial agonists, clinically available and safe drugs, may have great usefulness in the treatment of psychiatric illness, such as depression and anxiety.

It is well known that 5-HT1A receptors play an important role in the regulation of mood, anxiety, and cognition [15]. 5-HT1A receptors also have been shown to regulate hippocampal neurogenesis in the SGZ of the DG. Santarelli et al. [29] showed that 5-HT1A receptordeficient mice did not respond to chronic fluoxetine treatment, as measured by the change in neurogenesis. Reporting on the effect of 5-HT1A receptor agonists on neurogenesis, Banasr et al. [30] and Soumier et al. [31] showed increased granule cell genesis in the DG during treatment with 8-hydroxy-2dipropylaminotetralin hydrobromide $(8-\mathrm{OH}-$ DPAT), a 5-HT1A receptor full agonist. However, 8-OH-DPAT is a chemical reagent that is not available for clinical use. Of interest, Radley and Jacobs [32] reported that the acute administration of 5-HT1A receptor full antagonist WAY100635 decreased neurogenesis in the DG.

Based on previous reports by many authors and our studies described above, we hypothesize that hippocampal neurogenesis plays an important role in the clinical efficacy of 5-HT1A receptor partial agonists.

This study aimed to elucidate the potential therapeutic effect of 5-HT1A receptor partial agonists in the treatment of depressive and anxiety disorders, from the standpoint of neurogenesis.

\section{METHODS}

\section{Animals}

Male Sprague-Dawley rats (Kyudo Co., LTD., Tosu, Japan) weighing 150-200 g upon arrival were studied. They were housed individually in a temperature $\left(23 \pm 2{ }^{\circ} \mathrm{C}\right)$, humidity $(60 \pm 10 \%)$, and light-controlled room (reverse 12-h light/dark cycle, lights off at 7:00 a.m.). Food and water were available ad libitum. All animal care and use procedures were performed in compliance with the regulations established by the Experimental Animal Care and Use Committee of Fukuoka University, which are in accordance with the universal principles of laboratory animal care. 


\section{Drugs}

Tandospirone citrate was supplied by Dainippon Sumitomo Pharma Co., Ltd. (Osaka, Japan). The drug was dissolved in saline and prepared at a concentration of 1 or $10 \mathrm{mg} / \mathrm{mL}$, then injected subcutaneously in a volume of $1 \mathrm{~mL} / \mathrm{kg}$. The control animals were given the same volume of vehicle solution. The dosage of TDS was chosen on the basis of previous reports [23, 33]. One week following the arrival of the animals at the laboratory, they were injected with either the vehicle or TDS (1 or $10 \mathrm{mg} / \mathrm{kg}$ ) once daily for 14 days.

\section{Novelty Suppressed Feeding (NSF) test}

Novelty Suppressed Feeding test was performed as previously described [34-36]. Briefly, animals were fasted for $24 \mathrm{~h}$, then placed in a corner of a large polypropylene tub $(50 \times 40 \times 20 \mathrm{~cm})$ with a food pellet positioned in the center. The time to the first chewing of the food (latency) was recorded. The test was continued for $12 \mathrm{~min}$ and if the animal had not eaten the result was scored as $12 \mathrm{~min}$. To evaluate the acute effect of TDS, the rats were initially injected with the vehicle or TDS, then $20 \mathrm{~min}$ later subjected to the first NSF test. In the experiment investigating the chronic effect of TDS, drug treatment was done for 14 days, and the next day the rats were subjected to the second NSF test.

\section{Brain Slice Preparation}

Two hours after termination of the second NSF test, the rats were deeply anesthetized with sodium pentobarbital and perfused transcardially with saline $(1,000 \mathrm{~mL} / \mathrm{kg})$ followed by $250 \mathrm{~mL}$ of $4 \%$ ice-cold paraformaldehyde in $0.1 \mathrm{M}$ phosphate buffered saline (PBS; $\mathrm{pH}$ 7.4). The brain was removed from the skull and post-fixed overnight in the same fixative at $4{ }^{\circ} \mathrm{C}$, then placed into graded concentrations of sucrose in PBS at $4{ }^{\circ} \mathrm{C}$. Coronal sections of the brain were cut $(30 \mu \mathrm{m}$ sections) through the entire hippocampus (bregma -1.72 to $-6.84 \mathrm{~mm}$ [37]) on a freezing microtome. Sections were mounted onto silane-coated glass slides, then dried and stored at $-80{ }^{\circ} \mathrm{C}$ prior to processing.

\section{Immunohistochemistry}

After washing in PBS, sections were incubated for $30 \mathrm{~min}$ in $3 \% \mathrm{H}_{2} \mathrm{O}_{2}$ to eliminate endogenous peroxidases. After blocking with 5\% normal goat serum, the sections were incubated with anti-doublecortin (DCX) primary antibody (rabbit, 1:1,000; Abcam, Cambridge, UK) overnight at $4{ }^{\circ} \mathrm{C}$. They were then incubated for $2 \mathrm{~h}$ with secondary antibody (biotinylated goat anti-rabbit, 1:200; Vector Laboratories, Burlingame, CA, USA) followed by amplification with an avidin-biotin complex (1:300; DAKO Japan, Kyoto, Japan), and the cells were visualized with diaminobenzidine (DAB) (Vector Laboratories, Burlingame, CA, USA). The sections were air-dried and counterstained with hematoxylin, then dehydrated, cleared in xylene, and coverslipped.

\section{Stereological Analysis of DCX-Positive Cells in DG}

The total number of DCX-positive cells was counted throughout the rostrocaudal extent of the DG of granule cell layer (GCL) using a $40 \times$ objective (Nikon E600, Nikon, Tokyo, Japan). The optical fractionator method was used for counting, as previously described with minor modifications [30]. Briefly, in every section, the 
contour of the GCL/SGZ was first delineated for counting using the tracing function of the StereoInvestigator (MicroBrightField Japan, Chiba, Japan) software. Following this, the optical fractionator component was activated by entering parameters such as the grid size, the thickness of the guard zone, and the optical dissector height. A computer-driven motorized stage then randomly determined the counting frame locations. The StereoInvestigator software used the optical fractionator formula to calculate the total number of DCX-positive cells per DG. Every eighth section throughout the DG was analyzed, yielding a mean of 20 sections per brain. The total number of DCXlabeled cells in the GCL together with the SGZ, which is defined as a two-cell-body-wide zone along the border of the GCL, was estimated. This procedure ensured a systematic random sample of the sections, in which all parts of the DG region analyzed had the same opportunity of being represented. The precision of estimates of the number of cells was expressed using the coefficient of error (CE). The stereological sampling scheme was considered adequate when CE was less than 0.10 [38].

\section{Statistical Analysis}

One-way factorial analysis of variance (ANOVA) was performed to test for differences in latency in the NSF test and for quantification of DCXpositive cells, followed by Bonferroni/Dunn post hoc analysis for further examination of group differences. For the NSF test, the KaplanMeier method with Mantel-Cox log-rank test was used to determine differences in survival curves where the latency to eat was the limit of survival as previously described [25]. All data are represented as mean \pm standard error of the mean (SEM). $P$ value of $<0.05$ was adopted for significance.

\section{RESULTS}

\section{The Effects of Tandospirone in the NSF test}

The acute effect of TDS in the NSF test was examined immediately after the first injection of vehicle or TDS. TDS-treated animals performed significantly better than the vehicle-treated group (Kaplan-Meier survival analysis, Mantel-Cox log-rank test, $P=0.0145$; Fig. 1a, One-way ANOVA, $F_{2}, 1_{10}=5.753$, $P=0.0217$; Fig. 1b). Post hoc analysis further showed that acute treatment with high-dose TDS $(10 \mathrm{mg} / \mathrm{kg})$ produced a significant decrease in the latency to feeding relative to the vehicle$(P=0.0080)$ and TDS $(1 \mathrm{mg} / \mathrm{kg})$-treated rats $(P=0.0370)$. On the contrary, chronic TDS treatment did not have any behavioral effect on the latency to feeding compared with the vehicle-treated group (Fig. 1c, d).

\section{The Effects of Tandospirone on DCX- Positive Cells in the Dentate Gyrus of the Hippocampus}

Because of technical problems, brain samples for immunohistochemistry analysis could not be taken from three animals (one vehicletreated group, one TDS $1 \mathrm{mg} / \mathrm{kg}$-treated group and one TDS $10 \mathrm{mg} / \mathrm{kg}$-treated group). DCX is a protein expressed in immature newly born neurons that has recently been utilized to assess the level of neurogenesis [39, 40]. To assess the potential of TDS to modulate hippocampal neurogenesis, the number of DCX-immunopositive cells in the DG of the hippocampus was evaluated. Representative images of doublecortin-positive cells are shown in Fig. 2. DCX-labeled cells were observed mainly at the border of the GCL in the DG of the hippocampus (Fig. 2). The number of DCX-positive cells per volume of 
(a)

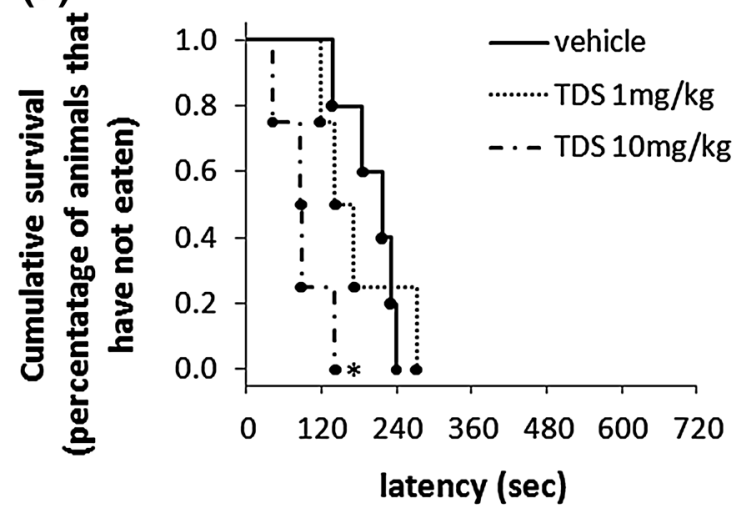

(c)

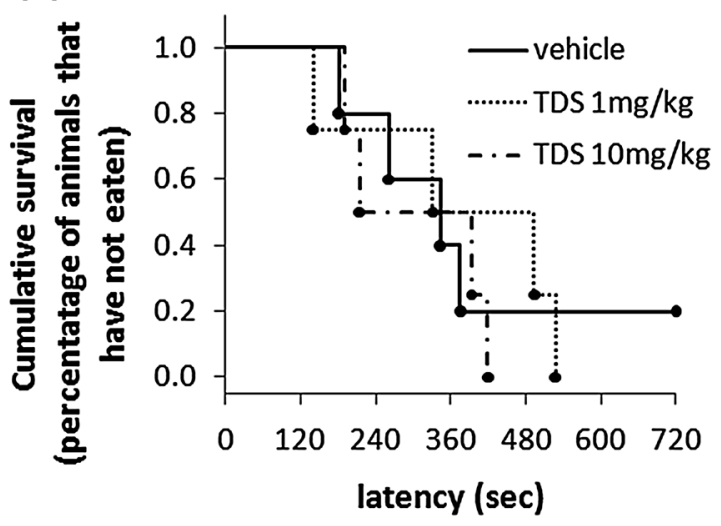

Fig. 1 Effects of acute and chronic tandospirone (TDS) treatment on the time to feeding (latency) in a Novelty Suppressed Feeding (NSF) test. The results are expressed as the cumulative survival of animals that have not eaten for over $12 \mathrm{~min}$ (left panel) or as the mean latency to feeding in seconds (right panel). The administration of TDS $(10 \mathrm{mg} /$ $\mathrm{kg}) 20 \mathrm{~min}$ prior to testing resulted in a significant reduction in the latency to feeding compared with a vehicle-treated group (a, b). However, no significant

DG was significantly increased in the TDStreated group compared with the vehicletreated group $\left(F_{2,} \quad 7=17.853, \quad P=0.0018\right.$; Fig. 3). Post hoc analysis identified significant differences between the vehicle-treated group and both the low and high dosage TDS-treated groups ( $P=0.0155, P<0.001$, respectively) and between the TDS $(1 \mathrm{mg} / \mathrm{kg})$ and TDS $(10 \mathrm{mg} /$ $\mathrm{kg})$-treated groups $(P=0.0368)$. However, no significant relationships between the number of (b)

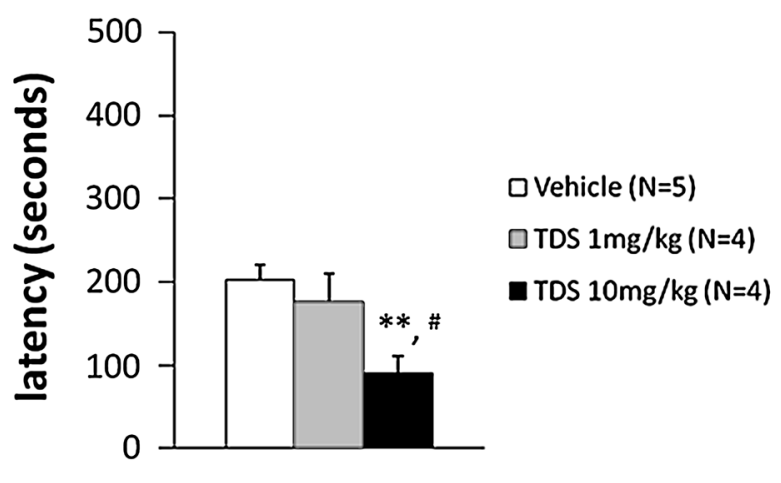

(d)

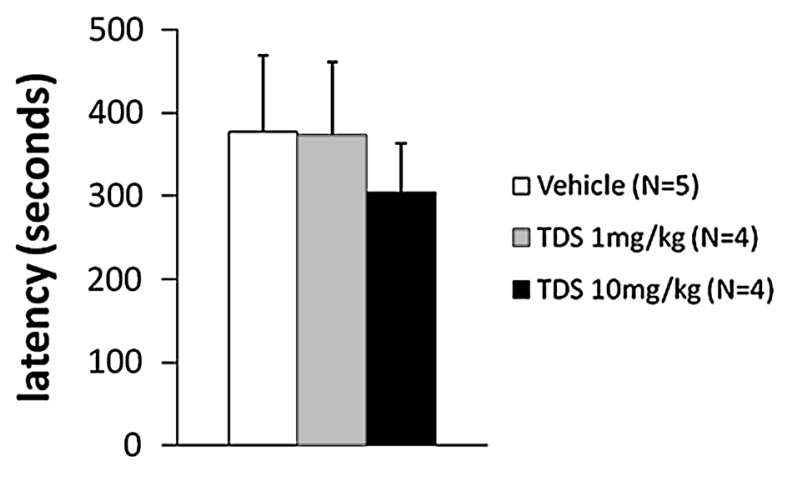

differences in the NSF test were observed between the vehicle- and TDS-treated groups $24 \mathrm{~h}$ after 14 days of TDS treatment (c, d). ${ }^{*} P<0.05,{ }^{* *} P<0.01$ vs. vehicle-treated group; ${ }^{\#} P<0.05$ vs. TDS $1 \mathrm{mg} / \mathrm{kg}$-treated group (KaplanMeier survival analysis, Mantel-Cox log-rank test or oneway ANOVA followed by Bonferroni/Dunn post hoc analysis)

DCX-labeled cells in the DG and the latency to feeding in the NSF test were found in the correlational analysis (data not shown).

\section{DISCUSSION}

In the present study, administration of TDS for 14 days increased the number of DCX-positive cells in the DG of adult rat hippocampus in a dose-dependent manner. This result suggests 
(a)
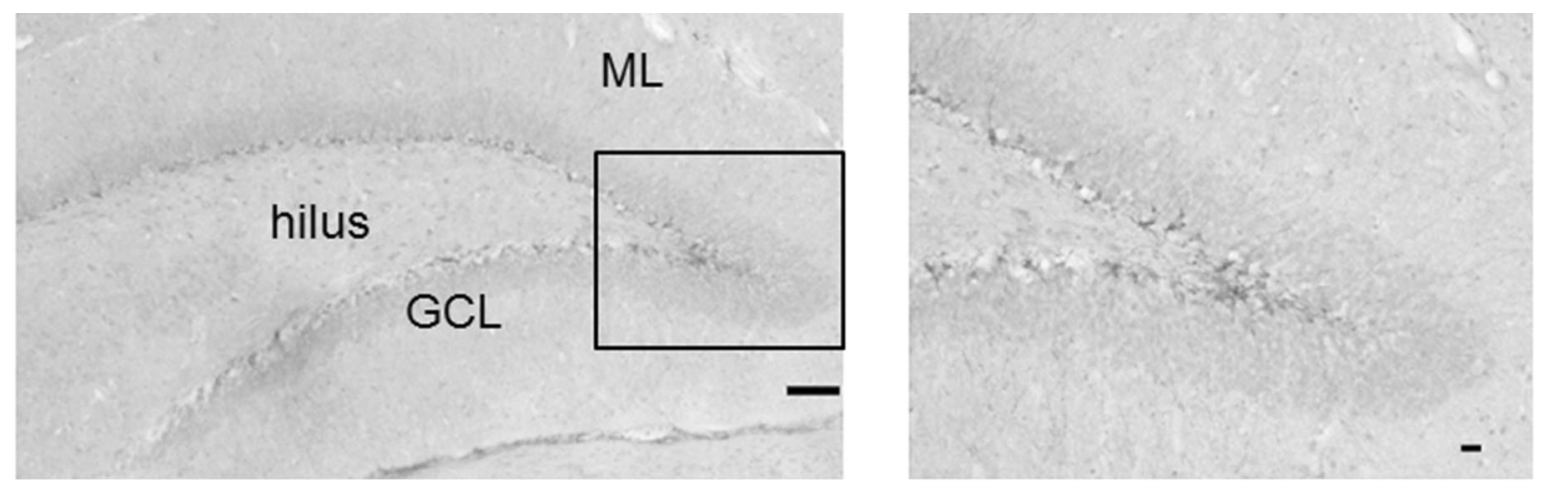

(b)

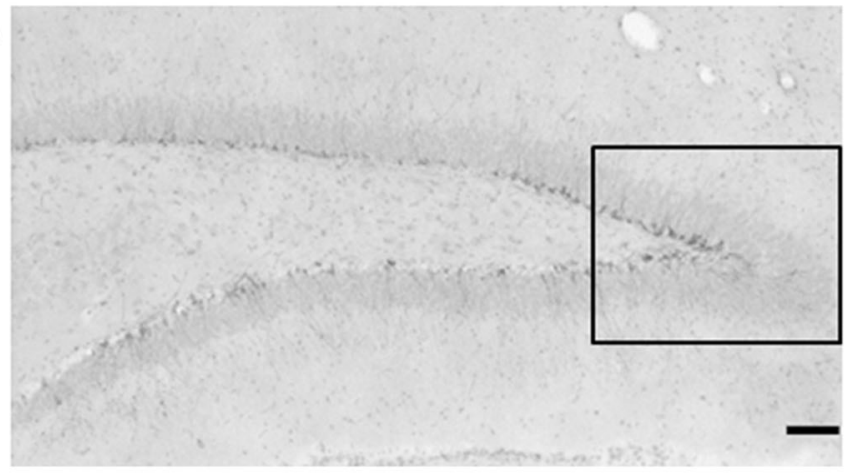

(c)
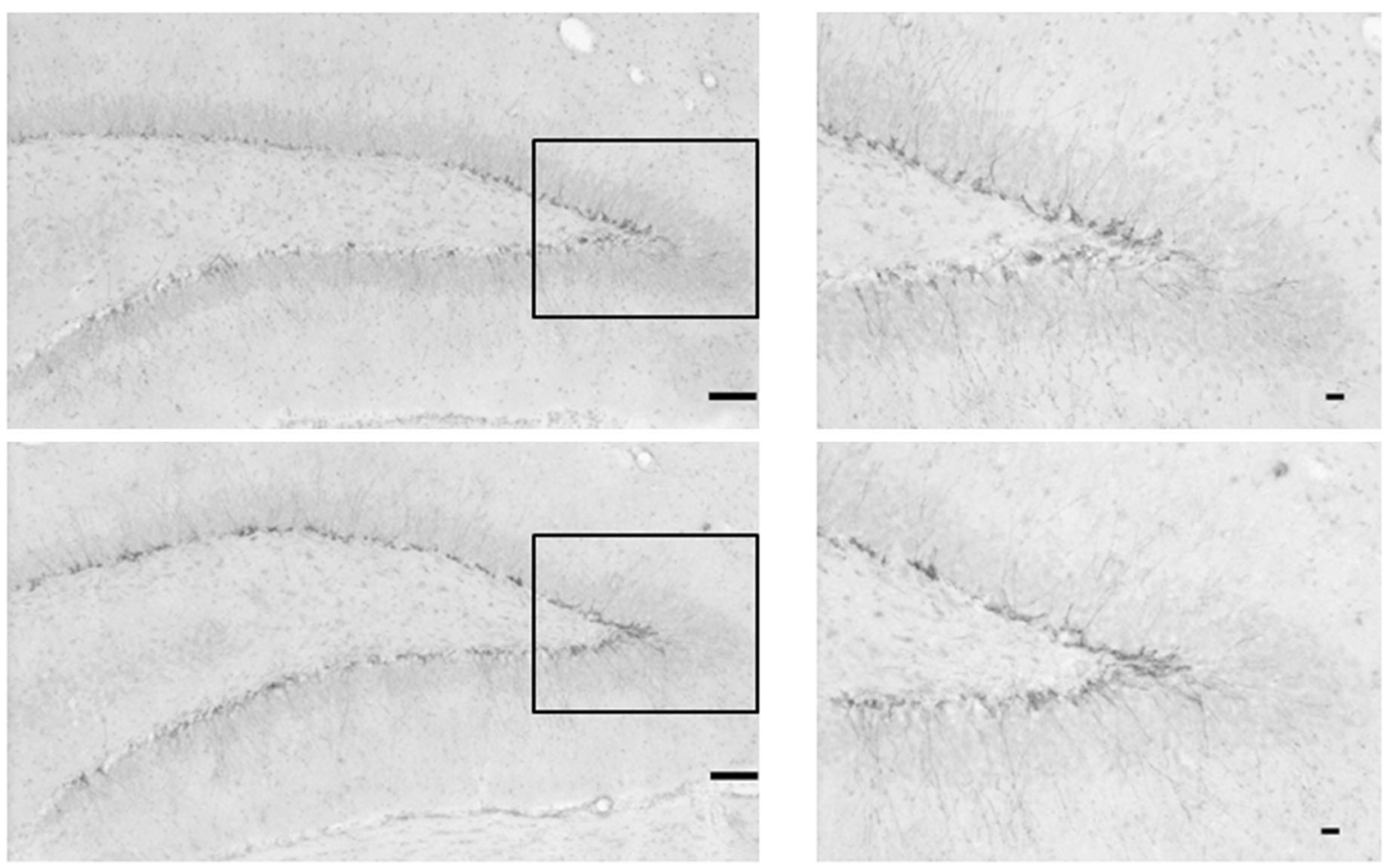

Fig. 2 Photomicrographs of doublecortin (DCX)-positive cells in the dentate gyrus of the rat hippocampus after chronic treatment (left, $\times 40$; right, $\times 100$ of the boxed region). DCX-positive cells were mainly located in the subgranular zone (SGZ). Vehicle-treated group (a). TDS

that chronic treatment with TDS increases hippocampal neurogenesis in humans, because DCX can be used as a quantitative marker of new nerve cells in the adult brain $[39,40]$. Adult hippocampal neurogenesis has been shown to be important for understanding and treating depression and anxiety [7]. Based on our result, we propose that 5-HT1A receptor partial
$1 \mathrm{mg} / \mathrm{kg}$-treated group (b). TDS $10 \mathrm{mg} / \mathrm{kg}$-treated group (c). GCL granule cell layer, $M L$ molecular layer (scale bars: left, $50 \mu \mathrm{m} ;$ right, $10 \mu \mathrm{m}$ )

agonists would be of great clinical usefulness for the treatment of depressive and anxiety disorders because of increased hippocampal neurogenesis. However, it will also be necessary in future studies to use other markers, such as Ki-67, NeuroD or NeuN, at each stage of neurogenesis and to assess the maturation index and synaptic branching in 


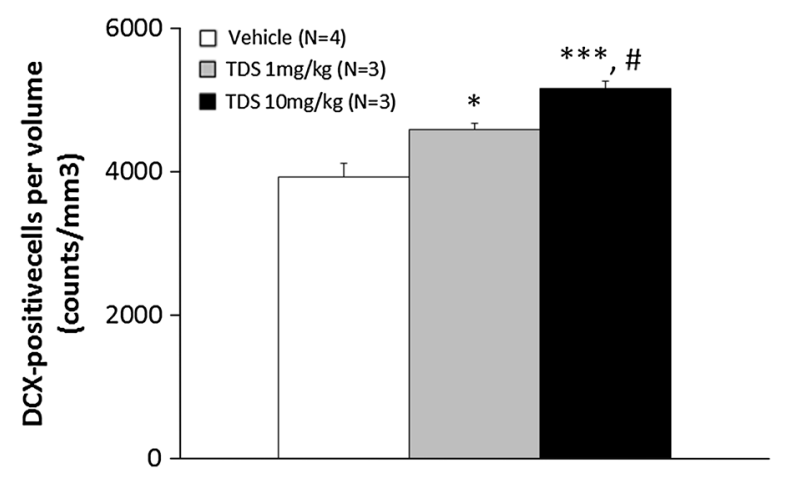

Fig. 3 Effects of chronic tandospirone (TDS) treatment on doublecortin (DCX) positive cells per volume of dentate gyrus (cells $/ \mathrm{mm}^{3}$ ). The density of DCX-positive cells was significantly increased by treatment with TDS for 14 days compared with the vehicle-treated group. The degree of increase in the density of DCX-positive cells increased by chronic TDS treatment was dose-dependent. ${ }^{*} P<0.05,{ }^{* * *} P<0.001$ vs. vehicle-treated group; ${ }^{\#} P<0.05$ vs. TDS $1 \mathrm{mg} / \mathrm{kg}$-treated group (one-way ANOVA followed by Bonferroni/Dunn post hoc analysis)

the hippocampal neurons to establish the relationship between 5-HT1A activation and the neurogenic effect on anxiolytic and antidepressant response.

To our knowledge, this is the first report to show chronic, positive effects of a 5-HT1A receptor partial agonist, a clinically available and safe drug, on hippocampal neurogenesis in rodents. Several studies have reported hippocampal neurogenesis using 5-HT1A receptor agonists or antagonists that are experimental reagents not available for clinical use. Banasr et al. [30] and Soumier et al. [31] found an increasing effect of 8-OH-DPAT, a 5-HT1A receptor full agonist, on granule cell genesis in the DG of the hippocampus of rodents, and Radley and Jacobs [32] reported that the acute administration of 5-HT1A receptor full antagonist WAY100635 decreases neurogenesis in the DG of the hippocampus of rodents. Further study will be necessary to determine if the administration of 5-HT1A receptor antagonists, such as WAY100635, block the increase in neurogenesis induced by chronic TDS administration.

The anxiolytic effect of 5-HT1A receptor partial agonists has been established and it has been shown that 5-HT1A receptor partial agonists have no remarkable adverse effects and little dependency. Furthermore, previous clinical trials suggest the possibility of 5-HT1A receptor partial agonists as useful drugs for the treatment of schizophrenia, eating disorders, Parkinson's disease, and cognitive dysfunction [41-46]. Recently, hippocampal neurogenesis has been associated with the etiology and treatment of neurodegenerative disorders, such as Parkinson's disease and Alzheimer's disease [47]. Also, Barbarich-Marsteller et al. [48] reported that hippocampal cell proliferation in the DG was reduced in an animal model of anorexia nervosa. Our results suggest the clinical usefulness of 5-HT1A receptor partial agonists for the treatment of such important diseases as those described above.

5-HT1A receptor partial agonists can also be used as augmentation therapy in conjunction with antidepressants for the treatment of depressive disorder [3]. Recent animal studies indicate that co-administering benzodiazepines with antidepressants prevents the SSRI-induced increase in hippocampal neurogenesis, although benzodiazepines are often used as anxiolytics in combination with antidepressants for depressive disorders, especially in the early phases of therapy when comorbid anxiety is present [16, 24, 25]. In contrast, our result suggesting that TDS treatment induces an increase in hippocampal neurogenesis helps explain the augmenting effect of 5-HT1A receptor partial agonists on their clinical efficacy for depressive disorders when administered in combination with an SSRI. 
In the present study, acute treatment with TDS significantly decreased the latency to feeding in the NSF test. The NSF test assesses anxiety behavior by measuring the time it takes an animal to approach and eat a familiar food in an aversive environment. Also, the NSF test is considered to be very sensitive to chronic treatment with antidepressants, including SSRIs [35]. Although it is difficult to prove that acute treatment with TDS exerts the same anxiolytic effect as chronic antidepressant treatment, this result suggests that TDS has specific efficacy for anxiety disorders. We also showed the anxiolytic effect of TDS using conditioned fear stress-induced freezing behavior in a previous study [23]. Thus, we have shown the excellent anxiolytic effect of TDS using two unique rodent models of anxiety behavior.

Of interest, several studies have indicated that there are relationships between hippocampal neurogenesis and behavioral changes in NSF testing of stress-exposed animals [29, 49]. However, in the present study, chronic treatment with TDS displayed no significant differences in the time to consumption of a food pellet in a NSF test, despite the finding of a significant increase in the number of DCX-positive cells. It will be necessary to carry out further studies to explain why this study failed to find behavioral change in rats chronically administered TDS. Restructuring of the experimental methodology should be considered, including changes in the duration of TDS administration, increasing the sample size of rats chronically administered TDS, and investigation of the effects of TDS in NSF testing that uses models of depressive animals exposed to stressors. In addition, a forced swim test, a novel animal model of depressive disorders, should be done to clarify the effect on the behavioral change of rats undergoing chronic TDS treatment.

\section{CONCLUSION}

In conclusion, this study strongly suggests that 5-HT1A receptor partial agonists are useful and beneficial for the treatment of depressive and anxiety disorders, from the standpoint of hippocampal neurogenesis.

\section{ACKNOWLEDGMENTS}

No funding or sponsorship was received for this study or publication of this article. Dr. Yusuke Murata is the guarantor for this article, and takes responsibility for the integrity of the work as a whole.

Conflict of interest. Masayoshi Mori, Yusuke Murata, Asami Matsuo, Tomoyo Takemoto, and Kazunori Mine declare no conflicts of interest.

Compliance with ethics guidelines. All institutional and national guidelines for the care and use of laboratory animals were followed.

Open Access. This article is distributed under the terms of the Creative Commons Attribution Noncommercial License which permits any noncommercial use, distribution, and reproduction in any medium, provided the original author(s) and the source are credited.

\section{REFERENCES}

1. Klenk MM, Strauman TJ, Higgins ET. Regulatory focus and anxiety: a self-regulatory model of GAD- 
depression comorbidity. Pers Individ Differ. 2011;50:935-43.

2. Kato M, Chang CM. Augmentation treatments with second-generation antipsychotics to antidepressants in treatment-resistant depression. CNS Drugs. 2013;27(Suppl 1):S11-9.

3. Trivedi HM, Fava M, Wisniewski RS, et al. Medication augmentation after the failure of SSRIs for depression. N Engl J Med. 2006;354:1243-52.

4. Rush AJ. Limitations in efficacy of antidepressant monotherapy. J Clin Psychiatry. 2007;68(Suppl 10):8-10.

5. Li X, Frye MA, Shelton RC. Review of pharmacological treatment in mood disorders and future directions for drug development. Neuropsychopharmacology. 2012;37:77-101.

6. Baldwin D, Woods R, Lawson R, Taylor D. Efficacy of drug treatments for generalised anxiety disorder: systematic review and meta-analysis. BMJ. 2011;342:d1199.

7. Petrik D, Lagace DC, Eisch AJ. The neurogenesis hypothesis of affective and anxiety disorders: are we mistaking the scaffolding for the building? Neuropharmacology. 2012;62:21-34.

8. Eriksson PS, Perfilieva E, Björk-Eriksson T, et al. Neurogenesis in the adult human hippocampus. Nat Med. 1998;4:1313-7.

9. Gould E, Gross CG. Neurogenesis in adult mammals: some progress and problems. J Neurosci. 2002;22:619-23.

10. Gould E, Tanapat P, McEwen BS, Flügge G, Fuchs E. Proliferation of granule cell precursors in the dentate gyrus of adult monkeys is diminished by stress. Proc Natl Acad Sci USA. 1998;95:3168-71.

11. Malberg JE, Eisch AJ, Nestler EJ, Duman RS. Chronic antidepressant treatment increases neurogenesis in adult rat hippocampus. J Neurosci. 2000;20:9104-10.

12. Fuchs E, Flügge G. Stress, glucocorticoids and structural plasticity of the hippocampus. Neurosci Biobehav Rev. 1998;23:295-300.

13. Samuels BA, Hen R. Neurogenesis and affective disorders. Eur J Neurosci. 2011;33:1152-9.

14. Blier $\mathrm{P}$, Ward NM. Is there a role for 5-HT1A agonists in the treatment of depression? Biol Psychiatry. 2003;53:193-203.
15. Polter AM, Li X. 5-HT1A receptor-regulated signal transduction pathways in brain. Cell Signal. 2010;22:1406-12.

16. Davidson JR. Major depressive disorder treatment guidelines in America and Europe. J Clin Psychiatry. 2010;71(Suppl E1):e04.

17. Chouinard G. Issues in the clinical use of benzodiazepines: potency, withdrawal, and rebound. J Clin Psychiatry. 2004;65(Suppl 5):7-12.

18. Chamberlain SR, Müller U, Deakin JB, et al. Lack of deleterious effects of buspirone on cognition in healthy male volunteers. J Psychopharmacol. 2007;21:210-5.

19. Lader M, Tylee A, Donoghue J. Withdrawing benzodiazepines in primary care. CNS Drugs. 2009;23:19-34.

20. Okamoto R, Itoh Y, Murata Y, Kobayashi D, Hosoi $\mathrm{M}$, Mine K. Reduction of group II metabotropic glutamate receptors during development of benzodiazepine dependence. Pharmacology. 2013;91:145-52.

21. Suzuki M, Uchiumi M, Murasaki M. Effects of tandospirone, a 5-HT1A receptor-related anxiolytic, on daytime sleepiness and psychomotor functions: a comparative doubleblind study with diazepam. Yakubutsu Seishin Kodo. 1993;13:213-24.

22. Evans SM, Troisi JR 2nd, Griffiths RR. Tandospirone and alprazolam: comparison of behavioral effects and abuse liability in humans. J Pharmacol Exp Ther. 1994;271:683-94.

23. Nishitsuji K, To $H$, Shimizu $T$, et al. The pharmacokinetics and pharmacodynamics of tandospirone in rats exposed to conditioned fear stress. Eur Neuropsychopharmacol. 2006;16: 376-82.

24. Wu X, Castrén E. Co-treatment with diazepam prevents the effects of fluoxetine on the proliferation and survival of hippocampal dentate granule cells. Biol Psychiatry. 2009;66:5-8.

25. Sun Y, Evans J, Russell B, Kydd R, Connor B. A benzodiazepine impairs the neurogenic and behavioural effects of fluoxetine in a rodent model of chronic stress. Neuropharmacology. 2013;72:20-8.

26. Yamada K, Yagi G, Kanba S. Clinical efficacy of tandospirone augmentation in patients with major depressive disorder: a randomized controlled trial. Psychiatry Clin Neurosci. 2003;57:183-7. 
27. Artigas F. Serotonin receptors involved in antidepressant effects. Pharmacol Ther. 2013;137:119-31.

28. Nishitsuji K, To H, Murakami Y, et al. Tandospirone in the treatment of generalised anxiety disorder and mixed anxiety-depression: results of a comparatively high dosage trial. Clin Drug Investig. 2004;24:121-6.

29. Santarelli L, Saxe M, Gross C, et al. Requirement of hippocampal neurogenesis for the behavioral effects of antidepressants. Science. 2003;301:805-9.

30. Banasr M, Hery $M$, Printemps R, Daszuta A. Serotonin-induced increases in adult cell proliferation and neurogenesis are mediated through different and common 5-HT receptor subtypes in the dentate gyrus and the subventricular zone. Neuropsychopharmacology. 2004;29:450-60.

31. Soumier A, Banasr M, Goff LK, Daszuta A. Regionand phase-dependent effects of 5-HT(1A) and 5-HT(2C) receptor activation on adult neurogenesis. Eur Neuropsychopharmacol. 2010;20:336-45.

32. Radley JJ, Jacobs BL. 5-HT1A receptor antagonist administration decreases cell proliferation in the dentate gyrus. Brain Res. 2002;955:264-7.

33. Sullivan NR, Crane JW, Damjanoska KJ, et al. Tandospirone activates neuroendocrine and ERK (MAP kinase) signaling pathways specifically through 5-HT1A receptor mechanisms in vivo. Naunyn Schmiedebergs Arch Pharmacol. 2005;371:18-26.

34. Bodnoff SR, Suranyi-Cadotte B, Aitken DH, Quirion $\mathrm{R}$, Meaney MJ. The effects of chronic antidepressant treatment in an animal model of anxiety. Psychopharmacology. 1988;95:298-302.

35. Bodnoff SR, Suranyi-Cadotte B, Quirion R, Meaney MJ. A comparison of the effects of diazepam versus several typical and atypical anti-depressant drugs in an animal model of anxiety. Psychopharmacology. 1989;97:277-9.

36. Marcussen AB, Flagstad P, Kristjansen PE, Johansen $\mathrm{FF}$, Englund $\mathrm{U}$. Increase in neurogenesis and behavioural benefit after chronic fluoxetine treatment in Wistar rats. Acta Neurol Scand. 2008;117:94-100.

37. Paxinos $G$, Watson $C$. The rat brain in stereotaxic coordinates. 6th ed. New York: Academic Press; 2007.
38. West MJ, Gundersen HJ. Unbiased stereological estimation of the number of neurons in the human hippocampus. J Comp Neurol. 1990;296:1-22.

39. Rao MS, Shetty AK. Efficacy of doublecortin as a marker to analyse the absolute number and dendritic growth of newly generated neurons in the adult dentate gyrus. Eur J Neurosci. 2004;19:234-46.

40. Couillard-Despres S, Winner B, Schaubeck S, et al. Doublecortin expression levels in adult brain reflect neurogenesis. Eur J Neurosci. 2005;21:1-14.

41. Tamai H, Komaki G, Kubota $S$, et al. The clinical efficacy of a 5-HT1A agonist, SM-3997, in the treatment of bulimia. Int J Obes. 1990;14:289-92.

42. Wilcox CS, Ferguson JM, Dale JL, Heiser JF. A double-blind trial of low- and high-dose ranges of gepirone-ER compared with placebo in the treatment of depressed outpatients. Psychopharmacol Bull. 1996;32:335-42.

43. Sato S, Mizukami K, Asada T. A preliminary openlabel study of 5-HT1A partial agonist tandospirone for behavioural and psychological symptoms associated with dementia. Int J Neuropsychopharmacol. 2007;10:281-3.

44. Ohno Y. Therapeutic role of 5-HT1A receptors in the treatment of schizophrenia and Parkinson's disease. CNS Neurosci Ther. 2011;17:58-65.

45. Lacivita E, Di Pilato P, De Giorgio P, et al. The therapeutic potential of 5-HT1A receptors: a patent review. Expert Opin Ther Pat. 2012;22:887-902.

46. Celada P, Bortolozzi A, Artigas F. Serotonin 5-HT1A receptors as targets for agents to treat psychiatric disorders: rationale and current status of research. CNS Drugs. 2013;27:703-16.

47. Enciu AM, Nicolescu MI, Manole CG, Mureşanu DF, Popescu LM, Popescu BO. Neuroregeneration in neurodegenerative disorders. BMC Neurol. 2011;11:75.

48. Barbarich-Marsteller NC, Fornal CA, Takase LF, et al. Activity-based anorexia is associated with reduced hippocampal cell proliferation in adolescent female rats. Behav Brain Res. 2013;236:251-7.

49. Snyder JS, Soumier A, Brewer M, Pickel J, Cameron HA. Adult hippocampal neurogenesis buffers stress responses and depressive behaviour. Nature. 2011;476:458-61. 